\title{
Numeracy and migrant students: a case study of secondary level mathematics education in Norway
}

\author{
Guri A. Nortvedt ${ }^{1}$ (D) Eline Wiese ${ }^{1}$ (1) \\ Accepted: 2 February 2020 / Published online: 17 February 2020 \\ (c) The Author(s) 2020
}

\begin{abstract}
Previous research has shown that adults from migrant backgrounds often have lower numeracy competence than do their majority counterparts, even though many were educated in their host country. Leaving secondary education with lower levels of numeracy competence than majority students potentially makes migrant students vulnerable as adults, as the lack of numeracy competence can negatively impact their opportunities to participate in work-life and society, in addition to affecting their everyday lives. Thus, it is vitally important to understand how mathematics education at the compulsory level can offer migrant students opportunities to develop numeracy competence. This paper presents a case study of four Norwegian lower secondary mathematics teachers. These teachers were asked to reflect on their classroom practices and on how they adapt teaching and assessment situations to migrant students. Our findings show that the teachers valued diversity in their classrooms and that their teaching was student-centred, focused on assessment for learning and problem-solving practices. These are potential building blocks for culturally responsive teaching. However, the teachers mainly focused on language issues, while cultural aspects of classroom participation and mathematical activity were neglected. This paper argues that such views may potentially hinder the provision of equal opportunities for all students to become numerate and, therefore, may contribute to maintaining migrant students—and the migrant adults they will become—as a vulnerable group.
\end{abstract}

Keywords Culture $\cdot$ Migrant students $\cdot$ Equity $\cdot$ Numeracy $\cdot$ Culturally responsive mathematics education

\section{Introduction}

Numeracy skills and practices are key to adults' successful participation in society, enabling them to cope with work and everyday life (Gal et al. 2003). This is just as true for adult migrants, who now form part of the population of nearly every country, as it is for adults from majority populations. According to OECD (2016b), the Program for the International Assessment of Adult Competencies (PIACC) revealed that numeracy scores among migrant adults fall significantly below those of their majority counterparts in most participating countries. This is true even for those who migrated at a young age and received their education

Guri A. Nortvedt

g.a.nortvedt@ils.uio.no

Eline Wiese

e.f.wiese@ils.uio.no

1 Department for Teacher Education and School Research, University of Oslo, P.O. Box 1099, Blindern, 0317 Oslo, Norway in the host country (OECD 2016b). If society cannot provide young migrants with adequate opportunities to develop numeracy competence, they have fewer opportunities to continue their education, and they become less attractive on the labour market. Indeed, the PIACC study also revealed that migrants earn lower wages and have lower rates of advancing to higher education and/or to continued education that promotes literacy and numeracy (OECD 2016b) Without numeracy competence, migrant adults are more likely to fall outside the regular workforce and are more likely to need social support and benefits. These factors make migrants vulnerable in a world that is rapidly changing, where specialised skills and educational degrees are vital.

According to Gal et al. (2003), being numerate means having "the knowledge and skills required to effectively manage and respond to the mathematical demands of diverse situations" (p. 4). Today, with increased migration, numeracy skills may be even more crucial as a gateway to participation in a new society. However, the Programme for International Student Assessment (PISA) study revealed differences in the mathematical literacy learning outcomes of 
migrant and majority students, with migrant students scoring significantly below their majority counterparts in most participating countries (OECD 2016a). Sometimes migrant students' scores even fell below those of students in their home country (Arikan et al. 2017). Inconsistencies in the direction and magnitude of the differences found in the PISA study, both within and across countries, suggest that the observed differences do not indicate a problem with the students. Instead, they are an outcome of the educational services offered to migrant students (OECD 2015). In addition, close to 20 years of data from the PISA study shows that many within the current adult migrant population left secondary school with low levels of mathematical literacy. This 'achievement gap' between migrant and majority students concerns educationalists as well as decision-makers. It constitutes an equity issue related to the effectiveness of educational systems, schools, and teachers, in providing migrant students with an education that prepares them for continued education and work-life (Miller-Jones and Greer 2009; Moschkovich and Nelson-Barber 2009; OECD 2015; Taguma et al. 2009).

An understanding of how secondary level education in the host country can contribute to migrant students' numeracy competence, is therefore, of crucial interest and can inform policy development and enhance the equity of education provided to migrant and majority populations. In many educational systems, compulsory education is intended to provide students with a foundation for developing numeracy skills (Geiger et al. 2015). However, numeracy is rarely taught as a separate subject. Rather, mathematics education is seen as providing the main opportunity for students to acquire the skills and knowledge that comprise numeracy competence (Gravemeijer et al. 2017).

This paper considers mathematics education at the secondary level in Norway as an appropriate context in which to examine how teachers' conceptions of mathematics and of migrant students influence their practices in accommodating such students. Providing equal opportunities for all students has been a priority goal of the Norwegian education system since World War II and is a key element in the Nordic model of education (Blossing et al. 2014). However, Taguma et al. (2009), in their policy review of migrant education in Norway, stated that although Norway maintains an inclusive educational system and undertakes numerous measures to improve migrant education, the gap between migrant and majority students' academic performance is still large. Their main advice to educational authorities in Norway was to improve teachers' capacity to be responsive to linguistic and cultural diversity in their schools and classrooms so that they can better adapt their teaching to individual students.

The differences in numeracy competence levels between migrant and majority populations show migrants to be a vulnerable group regarding mathematics education at the secondary level and, as such, at risk of lower numeracy competence compared to other groups in society. Vulnerability should not be seen as an inherent quality, but rather as one that depends upon the life circumstances and social conditions of the person in question (Gal et al. 2020). For young people attending school, the circumstances and conditions for learning and participating in the mathematics education that builds a foundation for their numeracy skills depend on teachers' insights into students' challenges, needs and potential. Therefore, it is vital that we understand how mathematics teachers think about migrant students, teaching and learning in their classrooms, and how this thinking contributes to students' numeracy levels. It is only with a deep understanding of these matters that we can enable equity in education. Equipped with that understanding, we can envision how changes might be implemented to achieve more culturally aware and equitable processes. We can then foster more equal opportunities for all students to become numerate. To that end, this paper presents the outcomes of a case study of four Norwegian lower secondary mathematics teachers, investigating their conceptions of mathematics education and of migrant students and how they adapt their teaching and assessment practices to accommodate migrant students' development of numeracy competence.

Migrant students are students who were born abroad or who have at least one parent who was born abroad. Collectively, migrant students are a diverse group. However, as our focus in this paper is on how teachers view mathematics education and migrant students, and how their views might accommodate their students' development of numeracy skills, we are less concerned with formal definitions, or subgroups of migrants, as teachers in Norwegian schools need to accommodate all students, regardless of their backgrounds (Lovdata 2006).

\section{Previous research}

In this section we discuss factors relating to migrant students' development of numeracy competence in compulsory education, emphasising mathematics teaching, learning, and assessment. We explore factors that can hinder migrant students, or prevent them from realising the same extent of participation as their counterpart majority students, as well as factors that contribute to the possibility of participation by all students on equal terms.

\subsection{Numeracy}

Defining numeracy is not easy. Over time, several definitions have been introduced that focus on different aspects of handling numbers or mathematical competence that target students in compulsory education or adults (Carpentieri 
et al. 2009). According to Gravemeijer et al. (2017), numeracy frameworks often focus primarily on daily routines and citizenship, sometimes not distinguishing between work and everyday life. In much of the previous research, numeracy was primarily associated with the demands of adult life, but in connection with childhood and school-based learning, where the foundation for learning mathematics and becoming numerate is established. More recently, the concept of numeracy has been broadened to include competencies such as the ability to communicate, interpret, employ and evaluate mathematical information in situations related to social and work life, education and reflective citizenship (see Gal et al. 2020).

Geiger et al. (2015) defined numeracy as "a term used to identify the knowledge and capabilities required to accommodate the mathematical demands of private and public life and to participate in society as informed, reflective, and contributing citizens" (p. 531). A more fine-tuned definition can be found in the PIAAC framework, which describes numeracy as the ability to access, use, interpret and communicate mathematical information and ideas in order to engage in and manage the mathematical demands of a range of situations in adult life (Gal et al. 2009; OECD 2016b). Being not only competent but also confident and inclined to use one's mathematical competence to solve embedded problems is a crucial part of numeracy (Carpentieri et al. 2009). In other words, simply being able to apply mathematical knowledge and skills is not sufficient. As such, compulsory education might substantially contribute to students' numeracy levels by focusing on applied mathematics, the mathematics of everyday life, critical mathematics education or twentyfirst-century skills and by including opportunities for students to develop a productive disposition toward applying their mathematical competence to handle situations in their everyday lives, continued education, society and work-life (Geiger et al. 2015; Skovmose 1994).

\subsection{Student-centred mathematics education could foster numeracy competence}

Traditionally, mathematics teaching has been teacher-centred, aiming to teach students concepts and skills they can later reproduce to solve mathematical tasks with a focus on solving stereotypical problems. With the introduction of more student-centred mathematics education, approaches such as classroom discourse, problem-solving and modelling were introduced. These learning approaches, according to Geiger et al. (2015), are more appropriate to develop students' numeracy skills, since they can teach students how to use their competence to solve real-life tasks (Blomhøj and Jensen 2007), tackle large data sets and develop critical mathematical thinking (Skovmose 1994).
According to Greer and Mukhopadhyay (2015), mathematics education makes sense only "when considered as embedded in historical, cultural, social, and political-in short, human-contexts" (p. 261). This consideration is also relevant to numeracy education. Previous research has shown that what we view as mathematics is, in itself, cultural (Gay 2009), whether we think only of pure mathematics or we include contextual or applied mathematics (Miller-Jones and Greer 2009). In addition, very different understandings of what it means to learn mathematics will emerge from teacher-centred versus student-centred classrooms, with student-centred classrooms more focused toward contextual mathematics (Miller-Jones and Greer 2009; Moschkovich and Nelson-Barber 2009).

\subsection{Culturally responsive mathematics education}

The notion of culturally responsive mathematics education emerged some time ago. It emphasises that teachers should adapt mathematics teaching and learning activities to students' ways of communicating and interacting, whilst being aware of students' prior experiences, culture and language, so as to enhance their opportunities for learning mathematics (Moschkovich and Nelson-Barber 2009). For this reason, teachers must be aware of culture and language issues and how they relate to teaching and learning mathematics (Barwell 2009; Civil and Hunter 2015; Moschkovich 2007). Therefore, culturally responsive mathematics teaching, including assessment, is student-centred (Miller-Jones and Greer 2009; Moschkovich and Nelson-Barber 2009) and emphasises a reciprocal relationship among members of the teaching-learning community (Nicol et al. 2013). In other words, rather than acculturating students to the majority socio-mathematical norms, norms are negotiated and developed within the classroom community (Hodge and Cobb 2016). Previous research indicates that culturally responsive mathematics education is beneficial to both majority and minority students (Nicol et al. 2013).

Early research on culturally responsive mathematics education, especially in the United States, focused mainly on bilingual classrooms or classrooms where students came from two identified cultures, one of which was considered the minority (see Hodge and Cobb 2016). In this context, advice for teachers typically related to getting to know the minority culture and (if possible) its language and using activities familiar to minority students as contexts for mathematical problems (e.g., Civil 2002). Even though this practice might be appropriate to create relevant and motivating contexts in which students can engage in mathematical activities that foster numeracy skills, this orientation views culture as a way of life characteristic of a bounded community (Hodge and Cobb 2016). Hodge and Cobb (2016) proposed that, with more diverse classrooms, it may be more 
fruitful to establish shared classroom norms that enable all students to participate in teaching and learning activities. Civil and Hunter (2015) showed how negotiating classroom norms can create mathematics classrooms that enable diverse students to participate in problem-solving activities involving real-life problems that are relevant to the students. As such, culturally responsive mathematics education in diverse classrooms is student-centred and oriented toward problem-solving, enabling all students to participate substantially. This is crucial for promoting inclusion and equity, as well as for providing all students with opportunities to develop numeracy competence.

\subsection{Language}

Language is a cultural resource. Through language, we express values and communicate (Moschkovich and Nelson-Barber 2009). Language is also the medium through which we learn and show what we know. Previous research has identified language as a factor contributing to student difficulties in learning (Barwell 2009; Barwell et al. 2016) and assessment situations (Abedi and Lord 2001). There is substantial focus on student vocabulary in the literature; however, although it is necessary, vocabulary alone is not sufficient (Moschkovich and Nelson-Barber 2009; Civil 2012). The interplay between mathematical language and everyday language-for instance, involving words such as compare, decide, or establish-demands that students master both the everyday and mathematical registers, and the interplay between them, in order to engage in mathematical activity (Barwell et al. 2016). Dense mathematical language must also be unpacked, combining both symbolic and natural language. Prediger et al. (2016) introduced a third register, the school register, which is the language used in the mathematics classroom in teaching and learning situations that students must master to access learning content and practices.

Previous research has demonstrated that allowing students to use their language resources in the mathematics classroom may benefit their learning and expand their access to mathematical practices, for example, by interpreting contexts, representing quantities, modelling real-life situations and communicating (Barwell et al. 2016). However, many teachers focus mainly on using the majority language of instruction.

\subsection{Authority and power}

Another question pertinent to this study relates to who has authority in mathematics education (Civil 2012). Klenowski (2009) asked whose knowledge is taught, stating that the view of mathematics and mathematics education held by the majority is usually what is considered valid. Furthermore, the content that is considered valid also influences what knowledge is assessed and equated with achievement (Stobart 2005). Culturally fair teaching and assessment practices can be related to students' opportunities to participate in learning activities (access) and to demonstrate what they have learned (validity and fairness). In assessment situations, language might hinder students' participation (Abedi and Lord 2001). Moschkovich (2007) argued that it is necessary to move from teaching and assessing words, to teaching and assessing mathematical content-allowing students to express mathematical ideas in different modes.

It may be easier for teachers to adapt formative assessment practices to their students, in order to focus on how students interpret, solve and evaluate contextual problems. Miller-Jones and Greer (2009) argued that assessment for learning may be a culturally valid means of assessing and supporting migrant students' learning. They viewed assessment as communication and suggested that, in order to provide culturally responsive assessment for learning, teachers need knowledge about numeracy, didactical knowledge and knowledge about diverse students (Gay 2009; Miller-Jones and Greer 2009).

All students can be successful and become numerate if their teachers believe they can learn and help them link their understanding of mathematical ideas and concepts to cultural referents (Ladson-Billings [1995] in Gay 2009). Comparing highly effective elementary schools with average elementary schools, Kitchen et al. (2009) found that teachers in highly effective schools had better developed conceptions of mathematics education and student diversity, including their views and expectations of their students' success. From the results of previous research, authors have reported that many mathematics teachers believe migrant students are less capable than majority students (Moschkovich and Nelson-Barber 2009) and sometimes employ deficit thinking (Nicol et al. 2013). Such beliefs 'turn' migrant students into a vulnerable group, since a teacher's belief that certain students have deficits can negatively impact the teacher's ability to offer classroom activities and opportunities for their students to learn vital skills, such as numeracy, thus impacting the students' future lives. For instance, believing that students' lack of mastery of the language of instruction is the 'problem' might induce teachers to provide only computational tasks rather than engaging students in rich contextual problems. This deprives the students of the foundation for becoming numerate.

Rousseau and Tate (2003) identified mathematics teachers' views on equity and equality as the main obstacles to equitable teaching practices that give all students the best possible opportunities for learning. While some teachers are oriented toward the learning process and attempt to treat all students the same way, others are oriented toward the product or learning outcome, adapting their teaching and offering 
learning activities to enable individual students to access content. According to Rousseau and Tate (2003), only the latter should be seen as focusing on equity; they indicate that teachers who focus solely on equality are, in reality, 'colourblind'. By overlooking cultural and other differences in their students, teachers not only overlook important aspects of student identity, but they also risk overlooking differences that hinder learning.

\section{The Norwegian educational context}

The Norwegian educational system is inclusive and, according to the Norwegian Education Act, teachers are required to adapt their teaching to the needs of the individual student, in order to provide all students with the best possible opportunities for learning (Lovdata 2006). A review by Roos (2019) revealed several dimensions to inclusion and indicated that inclusion in educational research is used to refer to an ideology and to a way of teaching. The Norwegian Education Act might feature both of these understandings of inclusion: (1) inclusion as a general principle or ideology, determining that no student should be excluded from education or the local school (Imsen et al. 2016); and (2) differentiation.

In Norway, the main approach to teaching is the wholeclass approach. Students have the right to attend their neighbourhood school (Imsen et al. 2016). There is no streaming, there are no tracks, and very few private schools exist. After 6-12 months in a reception class (mottaksklasse), migrant students are transferred to a regular classroom at their local school. In Norway, an adult who lacks a basic education has the right to attend adult education, at least at the level of lower secondary education (Lovdata 2006). This is provided by public and municipal systems and, usually, via regular schools (Dæhlen et al. 2013). Adult education is evaluated and, in part, regulated by Skills Norway, a section under the Ministry of Education. Adult education teachers receive their training from the teacher education programmes targeted at compulsory and secondary education.

In 2012, 9 out of 10 adults enrolled in adult education at the lower secondary level had a migration background (Dæhlen et al. 2013), and this number is growing. In compulsory education, the Norwegian situation resembles that of the international community-classrooms are becoming more diverse, due to enhanced migration, and about $15 \%$ of all students in lower secondary school and $17 \%$ of students in upper secondary school have migration backgrounds. Migrant students are a diverse group, comprising students seeking asylum as well as children of families who migrate for work or family purposes.

Migrant students often have a different home language. Consequently, they learn mathematics while also learning the Norwegian language, and their home languages are most likely not used in instructional settings. In addition, many migrant students have parents who do not speak the language of instruction or who have little formal education. Thus, migrant students often have less access to parental support with homework and schoolwork. Finally, migrant students, particularly those who are refugees themselves, may not have been able to attend formal schooling prior to attending school in Norway. Student learning can be negatively affected when schools do not consider knowledge acquired in informal settings as valid previous knowledge, or when students fall short due to lack of formal knowledge.

\subsection{Numeracy in the Norwegian compulsory education mathematics curriculum}

In Norway, the mathematics curriculum is nationally regulated, with established competency goals for teaching and learning (Imsen et al. 2016). The national curriculum comprises general guidelines and principles, subject curricula and descriptions of five basic skills that should be addressed in all subjects. One of these is numeracy (NDET 2012). As in other Nordic countries, a main objective of compulsory mathematics education is to teach students to solve real-life problems and to develop a productive disposition towards applying their mathematical competence (NDET 2013). Numeracy, as a basic skill, is included in the new curriculum to be implemented in August 2020 as well; in the new curriculum, mathematics is considered the 'mother' subject of numeracy. Thus, in Norway, mathematics education is the primary source for providing students attending compulsory education with competence in numeracy.

In the Norwegian curriculum, numeracy is described as applying mathematics to different life situations. It comprises four aspects: identifying and describing situations where mathematics might be used; carrying out strategies and procedures to solve applied problems; communicating; and reflecting on and evaluating the outcomes of problemsolving (NDET 2012). The PISA framework (OECD 2013) has influenced the definition of numeracy as a basic skill. A resemblance to the PIAAC framework processes can also be found, although the contexts and mathematical strategies included in numeracy are not specified in the curriculum. Rather, numeracy relates to being both able and inclined to apply mathematical competence to solve real-life problems. This means that, unlike many numeracy frameworks (e.g. Geiger et al. 2015), where statistical and financial literacy are emphasised in the numeracy definition, Norwegian basic numeracy skills involve aspects of the full content of the mathematics curriculum. 


\section{Methodology}

In this case study, four mathematics teachers from four Norwegian lower secondary schools were interviewed separately about their teaching and assessment practices, with a focus on how they adapted these practices to accommodate migrant students. The study is part of the Erasmus + Study: Aiding Culturally Responsive Assessment in Schools (ACRAS), a cooperative effort among four European partner universities in Austria, Ireland, Norway and Turkey (www.acras.eu). The case study protocol was developed by the four partners in cooperation.

\subsection{Sample and recruitment}

Five schools were recruited to take part in the Norwegian ACRAS case study. The schools comprised a purposive sample to represent a variety of Norwegian secondary schools. The sample included schools of different sizes, both in relation to student body and to the percentage of migrant students. All the schools were located within a 1-h drive from the University of Oslo. The sample included four public schools and one private school, representing different assessment orientations. Table 1 provides the schools' characteristics.

Volunteers were sought from the faculty within each school. The goal was to recruit one grade 8 mathematics teacher per school (teaching 13-year-old students, in the first year of the lower secondary level). In total, five mathematics teachers gave informed consent to participate in the study, but one teacher fell ill and was not interviewed. All the teachers were male, although the majority of Norwegian compulsory education mathematics teachers are female. The four teachers taught science in addition to mathematics. One teacher, David, had taught for only a few years; the other three had more experience. Carl had previously taught in a different school with more diversity.

\subsection{Interviews}

The interviews were semi-structured, following an interview guide comprising the topics of teaching, assessment formats and practices, teacher cooperation and professional development as they relate to migrant students' mathematics education. The international ACRAS interview guide was translated and adapted for interviewing staff in Norwegian secondary schools.

The interviews took place in the teachers' schools during the school day. They typically lasted $60 \mathrm{~min}$ and were audiotaped and transcribed by project members. Teachers could choose if they wanted to be interviewed individually or in pairs or groups. David was the only mathematics teacher interviewed in a group (with language and social science teachers). As this was a group interview, the teachers also reflected on each other's statements and experiences. Group interviews typically focused more on shared practices within the school than did the individual interviews. Consequently, David reflected less on his own teaching compared with Anders, Bjorn and Carl. However, his interview offered interesting insights into School D's assessment and school culture.

\subsection{Analytical procedures}

The transcribed interviews were analysed using content analysis (Mayring 2014). In the first inductive phase of the analysis, themes that would potentially become categories were identified. Several rounds of inductive analysis were performed to identify national themes. After each participating country had conducted its first inductive analysis, common categories were developed from emerging themes across the four countries: teachers' perceptions of relevant differences, concepts of fairness and validity, school policies, support structures and students' reactions/reflections. In addition, some national (Norwegian) categories were included in the deductive analysis in the second phase: conceptions of mathematics, teaching and assessment strategies,

Table 1 School characteristics

\begin{tabular}{|c|c|c|c|c|}
\hline & A (Anders) & B (Bjorn) & $\mathrm{C}(\mathrm{Carl})$ & D (David) \\
\hline Organisation & Public & Private & Public & Public \\
\hline Size & Medium & Small & Large & Medium \\
\hline Approaches to assessment & $\begin{array}{l}\text { Combines summative and } \\
\text { formative formats }\end{array}$ & $\begin{array}{l}\text { Summative in combination } \\
\text { with process-oriented } \\
\text { assessment formats; prac- } \\
\text { tices assessment without } \\
\text { grading in grade } 8\end{array}$ & $\begin{array}{l}\text { Combines summative } \\
\text { and formative formats; } \\
\text { attempts grade-free } \\
\text { schooling; policy to pro- } \\
\text { vide oral feedback }\end{array}$ & $\begin{array}{l}\text { Combines summative } \\
\text { and formative formats; } \\
\text { teachers should provide } \\
\text { oral feedback }\end{array}$ \\
\hline Teacher cooperation & $\begin{array}{l}\text { In grade-level teams and } \\
\text { inter-grade-level math- } \\
\text { ematics team }\end{array}$ & Across school and subject & $\begin{array}{l}\text { In grade-level teams and } \\
\text { across-grade-level math- } \\
\text { ematics team }\end{array}$ & $\begin{array}{l}\text { In grade-level teams and } \\
\text { across-grade-level math- } \\
\text { ematics team }\end{array}$ \\
\hline
\end{tabular}


language, conceptual understanding and beliefs about migrant students.

Following the deductive categorisation, teachers' beliefs were analysed based on the categorisation of individual teacher statements. Common beliefs and beliefs distinguishing teachers were identified. The goal of this analysis was to describe teachers' conceptions of migrant students and see how these conceptions related to their beliefs about mathematics, teaching and assessing mathematics, and opportunities for students to learn numeracy.

\section{Results}

The four teachers all expressed positive attitudes toward diverse classrooms. However, they also held views about mathematics, about migrant students and about teaching and assessment that may not foster the degree of equitable practices that the teachers intended, which could diminish migrant students' opportunities to learn mathematical content and develop numeracy skills.

\subsection{Views of mathematics and mathematics teaching}

During the interviews, three of the four teachers shared information about their teaching practices, describing student-centred classrooms where cooperation and communication were key means to enable student learning. Bjorn, for instance, described a mathematics lesson as follows: "So, I, we, launch a problem. And help them get started and then they figure it out, find a solution some way or another as I help out". He stated that he selected problems so that students could look for patterns, and that this was his main teaching method. In his own words, the goal was to foster student autonomy in a classroom where the teacher is "the scribe, and... they figure it out". In his classroom, this took place during whole-class discussion, whereas in Anders' and Carl's classrooms, students typically worked in pairs, as learning partners.

Applying mathematics to solve embedded problems potentially builds students' numeracy skills, provided the students also learn to recognise situations in which their knowledge applies. In addition, classroom activities should help students develop an inclination to use their competence (Geiger et al. 2015). Statements made by the four teachers supported the interpretation that their teaching, to some extent, could be characterised as preparing for numeracy. For instance, they viewed the purpose of lower secondary mathematics education as teaching for reflection, critical thinking and problem-solving. They saw this as challenging and described slightly different approaches to reach this goal, as follows.
Anders: So what is needed for students to succeed? It has to be to use language as much as possible, and if they are going to use the language as much as possible, then the teacher needs to shut up and allow the students to move the lesson forward... [Play-oriented problemsolving and exercises are] a method minority language students profit from, both because practical tasks do not require the same language skills, and because it allows them to speak Norwegian themselves-practicing speaking Norwegian.

While Anders stated that he emphasised classroom discourse, investigations and the use of language, Bjorn used a process-oriented practice in which students redrafted their mathematical texts. Carl explained that he focused on problem-solving and investigations. Although David spoke less about his teaching approaches, he was the only teacher who described involving students in writing learning goals for his mathematics lessons, or assessment criteria for mathematics assignments.

Whilst the teachers talked about teaching approaches consistent with teaching for numeracy, they also displayed beliefs about mathematics and mathematics education as being universal, indicating that they did not need to adapt their teaching to make classroom activities accessible for migrant students. Such views could prevent migrant and majority students from having equal opportunities for learning (Moschkovich and Nelson-Barber 2009). However, the teachers did not reveal the same understanding of 'universal'. Bjorn, for instance, claimed that mathematical procedures and mathematical language were universal, and that mathematical algorithms could be performed "in many languages". In contrast, Carl claimed:

Mathematics and science...[are], as I see it, relatively general areas. That is, there is not a huge difference in mathematics across countries. You have slightly different teaching approaches to the subject, sometimes there is more rote learning than perhaps here [in Norway]. But the maths is more or less the same, so I have not reflected much over this.

This indicates that Carl had some awareness that the purpose of mathematics education differs among countries. Anders may share Carl's view to some extent; he stated that students who attended primary school in Norway "...have been integrated into something you could call, for instance, the Norwegian model. So my impression is that they are just like other Norwegian children". Later, he explained that "the Norwegian model" comprised thinking mathematically in a way that supported problem-solving. However, Anders also stated that there are few cultural challenges related to teaching mathematics, indicating his belief that mathematics is culturally neutral. 
All four teachers mentioned language, expressing that language, to some extent and in some circumstances, was a barrier to participation for migrant students. Carl stated that teachers need to

...acknowledge... when you, for instance, design word problems, that it is, that...to many [students], it is more challenging because they need to interpret information provided in the task...Market? Vegetable? Words that you do not really reflect on when designing tasks. So you need to make certain that tasks are formulated clearly so that the main emphasis is on the mathematics rather than packing it [the mathematics] in different layers of language that need to be interpreted.

His statements resonated with aspects related to difficulties addressed in the literature (e.g., Barwell 2009; Moschkovich and Nelson-Barber 2009). He described the challenges students and teachers experience when migrant students do not have sufficient mastery over everyday concepts and do not have sufficient mastery of the language of instruction to comprehend contextual problems, stating that designing tasks using words students do not know is unnecessary. To address this issue, Carl systematically implemented tools to address conceptual understanding, such as mind maps and concept maps. He expressed that being aware of language issues was good pedagogy "for all students"; hence, it was also good for majority students:

...normal everyday words that they [migrant students] do not know. As I said, it varies a lot among students. That is, individual students soon learn a large vocabulary that perhaps comes from a European language and in reality has this concept-it is only named something different in their language, perhaps it is a little similar and can transfer. Then you have others coming from very different language groups who do not have the same learning progression of learning the language. They meet much larger challenges in the subject [mathematics].

Carl had prior experience teaching in diverse schools, and he reflected on the challenges individual students faced learning the language of instruction, depending on their home language and previous learning. Anders and Bjorn in particular addressed the classroom discourse, as in their classrooms, this was the main mode for learning new content. In this case, lack of mastery of the Norwegian language hindered participation as well as understanding and learning. The four teachers did not reflect on issues related to the relationship between language and culture; for instance, they overlooked cultural aspects of communicating.

\subsection{Adapting teaching and assessment practices to accommodate migrant students}

As all four mathematics teachers also taught science, they sometimes compared mathematics teaching to science teaching. They all claimed that they needed to adapt mathematics teaching and assessment activities to migrant students to a lesser extent than was the case for science, sometimes relating this to language. Analysis indicated that the teachers most likely adapted their teaching and assessment practices to differing degrees. For instance, Anders claimed to treat all students the same: "No, I have not been aware I should treat anyone [of the students] in a particular way". On the other hand, David involved the students in deciding for whom assessment should be adapted:

Mainly the whole class has the same [assessment format], but in some circumstances, I have chosen, independent of background, to let them choose if they want to have a written or oral [assessment] and really independent of background, let some have it [the test] orally. Either because of concentration difficulties, or if it is due to language issues, you make some deals [with students].

None of the four teachers seemed to view paper-andpencil tests as a primary source of knowledge about students' mathematical competence. Three of the four teachers claimed that they knew the level of students' mathematical knowledge from homework or lesson assignments.

The present analysis indicates that all four teachers adapted the assessment they use to accommodate migrant students. Anders, for instance, provided oral explanations of task content to a student transitioning from a reception class to his classroom. Carl said that he prepared students before assessment situations by working with model texts. He also used diverse task formats in tests, including tasks considered as reproductive as well as tasks that elicited reflection and justification. He thought all students, independent of background, should be able to solve some tasks. Bjorn taught at a school with an alternative pedagogical model. There, summative assessment formats included both paper-andpencil tests and written assignments. Adaptation typically concerned written assignments, where students were allowed to use different mathematical representations, such as drawings or even artwork, in addition to language.

All four teachers emphasised formative assessment or assessment for learning. They reflected on providing feedback to students, and they connected teaching, learning and feedback. They showed a preference for providing feedback orally rather than in writing, since oral feedback allowed for student-teacher interaction and involved the student's voice to a greater degree. 
In all four schools, the teachers said that peer assessment with grade eight students was challenging. David stated that they needed to practice with the students to help them learn how to provide valuable feedback to peers, such as offering "two stars and a wish", and that this was challenging. Bjorn and Carl used peer assessment often, with students providing feedback to each other on homework or writing tasks. Carl eased his students into self-assessment by working with goal sheets (målark) that provided students with learning goals and assessment criteria before starting a new topic.

\subsection{Experiences with and conceptions of migrant students}

Based on the statements of the four mathematics teachers, this study concluded that they all viewed diversity in itself as positive. David stated that students learn to work together across cultural backgrounds in a diverse school. They all emphasised inclusion, in the sense of participation in teaching and learning. For instance, they stated that extra tutoring should preferably be provided outside of regular mathematics lessons since, otherwise, students would be excluded from teaching-learning activities and from the learning community.

There are two sides to the teachers' conceptions of migrant students. On one hand, they each talked about participation in mathematics teaching and assessment activities, about socio-mathematical norms, for instance the "Nordic model" that Anders mentioned, and about language. It might be inferred that perceiving students as Norwegian when they know the Norwegian language is connected to the students' adaptation of the socio-mathematical norms of the classroom. However, some may question whether the teachers see their students as culturally diverse.

On the other hand, it seems that the teachers' interpretations of the inclusive Norwegian educational system and of inclusion in the Education Act made them want to view their students as "the same" rather than as diverse. Norwegian teachers are obliged to adapt their teaching to all students. Seemingly, the teachers did not see migrant students as a group for whom they target interventions; rather, ad-hoc solutions targeting individual migrant students and individual majority students are prioritised.

\section{Discussion and conclusions}

The main finding in our study is that the four mathematics teachers all focused on student-oriented classroom practices involving problem-solving, applied problems and investigations. Thus, important elements for developing numeracy competence were present in all classrooms (cf. Geiger et al. 2015). Other factors associated with classroom practices and teacher beliefs that might influence migrant students' opportunities to participate in classroom activities and become numerate were also found. For instance, the four teachers held positive attitudes toward inclusive education and aimed at adapting teaching and assessment to accommodate the migrant students in their mathematics classrooms. Moreover, the teachers attempted to involve their students in formative assessment activities, something that could contribute to student authority. These beliefs and practices align with the principles for culturally responsive mathematics education (cf. Miller-Jones and Greer 2009; Nicol et al. 2013) and may contribute to equity and promote numeracy competence in their students (cf. Civil and Hunter 2015; Rousseau and Tate 2003).

At the same time, however, the four teachers held beliefs that might work against their intentions to promote inclusive education that supports all students. For instance, they believed that mathematics is culture free. Moreover, their perceptions of students as Norwegian once the students had mastered the Norwegian language indicate that they struggled with tensions connected to inclusion, such as regarding their students as "the same". Furthermore, while the teachers showed awareness of language issues, they did not reveal cultural awareness and attention to students' backgrounds. Such tensions and views are identified in the research literature as threats to culturally responsive mathematics education and equity (cf. Moschkovich and Nelson-Barber 2009; Rousseau and Tate 2003). How these tensions might influence opportunities for migrant students to develop numeracy competence is discussed below.

\subsection{Issues related to participation}

The four classrooms were student-centred in both teaching and assessment practices. The teachers focused on engaging individual students in investigative- or discourse-oriented practices. The most talked about, and perhaps most important, assessment practice was assessment for learning and feedback. This foregrounding indicates that the teachers focused on adapting to individual students (Black and Wiliam 2012a, b; Moschkovich and Nelson-Barber 2009), perhaps contributing to the teachers' views that cultural characteristics were not differentiating factors at the individual level.

Students whose previous learning experiences were in teacher-centred classrooms may find it challenging to know how to act and participate in classroom discourse in student-oriented classrooms. This may be especially true during problem-solving and modelling exercises or in test situations, as well as when encouraged to demonstrate critical thinking and reflection (Civil and Hunter 2015). The four teachers showed awareness of this aspect; for instance, Anders and Carl expressed concerns about students who had 
previously attended classrooms where reproducing mathematical procedures and knowledge were the focus. However, they did not connect this with culture or participation. This may indicate that classroom norms enabling participation of all students (cf. Hodge and Cobb 2016; Civil and Hunter 2015) were not negotiated in these classrooms. Consequently, migrant students in these classrooms might have fewer possibilities to participate in classroom discourse and develop numeracy competence.

When the four teachers discussed how they adapted assessment or feedback situations, they mainly focused on language issues. It might be argued that, in their classrooms, adaptation meant facilitating participation or understanding in linguistically challenging situations. Language was viewed both as a key and as an obstacle to learning. The four teachers all found that language issues were emerging in their classrooms, and they connected this to migrant students' lack of mastery of the Norwegian language. However, they focused less on language as a cultural signifier (cf. Barwell 2009). This indicates that the teachers lacked an awareness of differences in students' ways of communicating, and thus, of how to successfully adapt teaching and assessment practices to the needs of specific students.

\subsection{Issues related to language and cultural awareness}

Anders, for instance, viewed students who had mastered the Norwegian language as Norwegian. Such views might indicate that, as part of viewing students as 'equal', the teachers thought of them as 'the same'. This understanding of inclusion could stand in the way of inclusive practices, such as recognising individual needs or differences and adapting to them (Roos 2019; Rousseau and Tate 2003). An alternative interpretation of the statement about "being Norwegian when speaking Norwegian" is connected to the meaning allocated to the concept of "migrant student" and who the teachers view as migrant, and this interpretation may indicate a lack of awareness of culture.

The lack of awareness of culture may indicate a tension surrounding the concepts of culture and cultural background in Norwegian schools.

We propose that students' level of mastery of the Norwegian language was used as a signifier for, or a way of 'explaining', cultural differences in understanding. A possible interpretation is that, in an inclusive educational system, addressing culture or ethnicity is challenging, as it focuses on differences (Rousseau and Tate 2003). This may be why the teachers instead addressed language issues, which may be viewed as less controversial. However, lack of cultural awareness can stand in the way of inclusion and, as such, hinder participation and learning for migrant students (Hodge and Cobb 2016). Moreover, a lack of attention to culture might stand in the way of acknowledging students' prior knowledge as valid knowledge (see Moschkovich and Nelson-Barber 2009) and, consequently, reduce student authority (Rousseau and Tate 2003).

Moreover, viewing mathematics as a culture-free and neutral subject also reflects the lack of awareness of culture and lack of awareness of students' culturally (different) ways of communicating (see Moschkovich and Nelson-Barber 2009). Migrant students are a heterogeneous group. To foster their numeracy competence, teachers should adapt their practices to enable students to build on their prior knowledge, to have access to content, and to participate on equal terms in teaching, learning and assessment situations.

Culture emerged as a central concept throughout the analysis in relation to teachers' views of mathematics, mathematics education and migrant students. Viewing mathematics as culture-free, rather than as a contextual practice, comes with a risk of focusing less on the interpretative and evaluative aspects of problem-solving (Moschkovich and Nelson-Barber 2009). In this way, it diminishes students' opportunities to work with mathematical problem-solving in ways that promote numeracy competence. This view of mathematics was observed frequently in previous research (e.g., Gay 2009; Moschkovich and Nelson-Barber 2009).

\subsection{Toward equitable practices that foster numeracy competence in migrant students}

The four teachers did not express ideas or reflections indicating that they thought less of migrant students compared to majority students, nor was there any indication that they held racist views. The learning of migrant and majority students was equally important to them and in line with the intentions of the Norwegian Education Act (Lovdata 2006) that highlights inclusion and differentiation to foster equity and equality. Applying student-centred practices, such as assessment for learning, the four teachers potentially gave authority and power to migrant students in their classrooms. However, in their intention to include migrant students in their classroom practices and in the community of learning in their classrooms, they seemingly overlooked students' backgrounds and cultures. In this sense, the extent to which student agency and authority was present might be questioned.

Student-centred teaching and assessment practices are a guiding principle in culturally responsive mathematics education (Gay 2009). Moreover, student-centred mathematics education focuses on problem-solving and applied problems, potentially building numeracy competence (Geiger et al. 2015). However, this Norwegian study indicates that, although classroom-level teaching and assessment practices were student-centred, and although teachers were aware of language issues and difficulties, translating this into cultural awareness is still to come. 
Moreover, lack of awareness of culture could make it challenging for teachers to identify appropriate contexts in which students can apply mathematical competence to reallife problems. Real-life problems potentially boost students' critical and mathematical thinking and are a crucial feature of numeracy learning (Skovmose 1994). Without exposure to appropriate problems, migrant students remain vulnerable.

Still, the observed practices represent a strong step towards equal opportunities for migrant and majority students to learn numeracy, and we argue that more culturally responsive practices are within reach. However, moving forward requires that teachers focus more on aspects of culture related to participation and communication in addition to language. Although our study was focused on mathematics education at the lower secondary level, we propose that awareness of culture is equally important in adult education, as this potentially could provide migrants possibilities to apply critical thinking in familiar contexts, something that could promote numeracy competence.

\subsection{Limitations and moving forward}

In the introduction to this paper, we discussed how the PISA study (OECD 2015) revealed that migrant students leave lower secondary education with lower levels of mathematical literacy compared to majority students, and how this is related to adult migrants having lower levels of numeracy competence than their majority counterparts. Thus, investigating how lower secondary education might contribute to migrant students' numeracy competence is crucial.

The current study involved only four male volunteer teachers from four schools, selected as a convenience sample. As such, there are several limitations to the study. The teachers were interviewed about their mathematics teaching and assessment activities. How these might foster students' numeracy competence was inferred from the data. The experiences, practices and reflections of these teachers cannot be taken to represent those of Norwegian teachers in general, yet the four interviews may provide illustrative examples of challenges facing teachers at the lower secondary level, in teaching migrant students and in preparing them for further education and adult life. The results of this study may help shed light on the gap between migrant and majority adults regarding differences in numeracy skills in Norway. Further, the current study may contribute to understanding how mathematics education at the secondary level might help to close this gap. Hopefully, this study can also provide a starting point for exploring similar phenomena in other countries or for more quantitatively oriented research.

Diverse classrooms are traditionally addressed in mathematics teacher education. However, the situation today is essentially the same as Taguma et al. (2009) described in their review, demanding that we find new strategies and ways to raise teachers' awareness. Building on the findings in the current study, we follow Heritage and Wylie (2018) in proposing assessment for learning as a promising tool to enhance the participation of migrant students. This was one of the tools the four teachers used, with which to engage and reach out to their students. However, more research is needed to investigate the relationship between assessment for learning practices and cultural awareness at the classroom level in compulsory and adult education.

In addition, we argue that for mathematics education to provide equal opportunities for all students to develop numeracy skills, a stronger emphasis on the cultural aspects of mathematical activity is necessary. This should include further research on relations between mathematics teaching and numeracy-across national curricula, education level and educational policy.

Finally, we argue that students who feel included in their mathematics classroom, who feel welcomed and respected by their teachers and have authority and agency regarding their own learning, are more likely to develop numeracy competence. This recommendation applies to adults as well as to secondary school students. The four teachers in this study all aimed to include their students and welcomed them in their classrooms. However, while some of their practices gave agency to the migrant students attending their mathematics classrooms, their lack of cultural awareness might reduce this agency, as they seemingly overlooked important aspects of the students' identities. Our final recommendation for further research is to investigate the relationship between cultural awareness, authority and classroom activities.

Acknowledgements Open Access funding provided by Oslo University \& Oslo University Hospital. The empirical study we report on herein is part of the Aiding Culturally Responsive Assessment in Schools (ACRAS) study. ACRAS is a strategic cooperation under the Erasmus + umbrella (Reference Number 2016-1-IE01-KA201-016889); see http://acras.eu/.

Open Access This article is licensed under a Creative Commons Attribution 4.0 International License, which permits use, sharing, adaptation, distribution and reproduction in any medium or format, as long as you give appropriate credit to the original author(s) and the source, provide a link to the Creative Commons licence, and indicate if changes were made. The images or other third party material in this article are included in the article's Creative Commons licence, unless indicated otherwise in a credit line to the material. If material is not included in the article's Creative Commons licence and your intended use is not permitted by statutory regulation or exceeds the permitted use, you will need to obtain permission directly from the copyright holder. To view a copy of this licence, visit http://creativecommons.org/licenses/by/4.0/.

\section{References}

Abedi, J., \& Lord, C. (2001). The language factors in mathematics tests. Applied Measurement in Education, 14(3), 219-234.

Arikan, S., van de Vijver, F. J. R., \& Yagmur, K. (2017). PISA mathematics and reading performance differences of mainstream 
European and Turkish immigrant students. Educational Assessment, Evaluation and Accountability, 29(3), 229-246.

Barwell, R. (2009). Summing up: Teaching and learning mathematics in a multilingual world. In R. Barwell (Ed.), Multilingualism in mathematics classrooms. Global perspectives (pp. 161-180). Bristol: Multilingual Matters.

Barwell, R., Chapsam, L., Nkambule, T., \& Phakeng, M. S. (2016). Tensions in teaching mathematics in contexts of language diversity. In R. Barwell, P. Clarkson, A. Halai, M. Kazima, J. Moschkovich, N. Planas, M. Setati-Phakeng, P. Valero, \& M. Villavicencio Ubillús (Eds.), Mathematics education and language diversity: The 21 st ICMI study (pp. 175-192). Cham: Springer.

Black, P., \& Wiliam, D. (2012a). Assessment for learning in the classroom. In J. Gardner (Ed.), Assessment and learning (pp. 11-32). London: Sage.

Black, P., \& Wiliam, D. (2012b). Developing a theory of formative assessment. In J. Gardner (Ed.), Assessment and learning (2nd ed., pp. 206-229). London: Sage.

Blomhøj, M., \& Jensen, T. H. (2007). What's all the fuss about competencies? In W. Blum, P. L. Galbrait, H.-W. Henn, \& M. Niss (Eds.), Modelling and applications in mathematics education: The 14th ICMI study (pp. 45-56). Boston, MA: Springer.

Blossing, U., Imsen, G., \& Moos, L. (2014). The Nordic education model. 'A school for all' encounters neo-liberal policy. Dordrecht: Springer.

Carpentieri, J. D., Litster, J., \& Frumkin, L. (2009). Adult numeracy: A review of research. London: National Research and Development Centre for Adult Literacy and Numeracy (NRDC).

Civil, M. (2002). Culture and mathematics: A community approach. Journal of Intercultural Studies, 23, 133-148.

Civil, M. (2012). Mathematics teaching and learning of immigrant students. In O. Skovsmose \& B. Greer (Eds.), Opening the cage: Critique and politics of mathematics education (pp. 127-142). Rotterdam: SensePublishers.

Civil, M., \& Hunter, R. (2015). Participation of non-dominant students in argumentation in the mathematics classroom. Intercultural Education, 26(4), 296-312.

Dæhlen, M., Danielsen, K., Strandbu, Å., \& Seippel, Ø. (2013). Voksne $i$ grunnskole og videregående opplaering [Adults in compulsory and upper secondary education]. Oslo: NOVA-Norsk institutt for forskning om oppvekst, velferd og aldring.

Gal, I., Alatorre, S., Close, S., Evans, J., Johansen, L., Maguire, T., et al. (2009). PIAAC numeracy. A conceptual framework. OECD education working paper no. 35. Paris: OECD Publishing.

Gal, I., Grotlüschen, A., Tout, D., \& Kaiser, G. (2020). Numeracy, adult education, and 'vulnerable' learners: A critical review of a neglected field. ZDM Mathematics Education, 52(2).

Gal, I., van Groenestijn, M., Manly, M., Schmitt, M. J., \& Tout, D. (2003). Adult numeracy and its assessment in the ALL survey: A conceptual framework and pilot results. Ottawa: Statistics Canada.

Gay, G. (2009). Preparing culturally responsive mathematics teachers. In B. Greer, S. Mukhopadhyay, A. B. Powell, \& S. NelsonBarber (Eds.), Culturally responsive mathematics education (pp. 189-205). New York: Routledge.

Geiger, V., Goos, M., \& Forgasz, H. (2015). A rich interpretation of numeracy for the 21st century: A survey of the state of the field. ZDM Mathematics Education, 47(4), 531-548.

Gravemeijer, K., Stephan, M., Julie, C., Lin, F.-L., \& Ohtani, M. (2017). What mathematics education may prepare students for the society of the future? International Journal of Science and Mathematics Education, 15(1), 105-123. https://doi.org/10.1007/ s10763-017-9814-6.

Greer, B., \& Mukhopadhyay, S. (2015). Honouring diversity in intercultural mathematics education. Intercultural Education, 26(4), 261-265.
Heritage, M., \& Wylie, C. (2018). Reaping the benefits of assessment for learning: Achievement, identity, and equity. ZDM Mathematics Education, 50(4), 729-741. https://doi.org/10.1007/s1185 8-018-0943-3.

Hodge, L. L., \& Cobb, P. (2016). Two views of culture and their implications for mathematics teaching and learning. Urban Education. https://doi.org/10.1177/0042085916641173.

Imsen, G., Blossing, U., \& Moos, L. (2016). Reshaping the Nordic education model in an era of efficiency. Changes in comprehensive school projects in Denmark, Norway, and Sweden since the millennium. Scandinavian Journal of Educational Research. https:// doi.org/10.1080/00313831.2016.1172502.

Kitchen, R. S., Roy, F. C., Lee, O., \& Secada, W. G. (2009). Comparing teachers' conceptions of mathematics education and student diversity at highly effective and typical elementary schools. Journal of Urban Mathematics Education, 2(1), 52-80.

Klenowski, V. (2009). Australian indigenous students: Addressing equity issues in assessment. Teaching Education, 20(1), 77-93.

Lovdata. (2006). Forskrift til opplaringsloven [Regulations of the education act]. https://lovdata.no/dokument/SF/forskrift/2006-06-23724. Retrieved July 10, 2018.

Mayring, P. (2014). Qualitative content analysis: Theoretical foundation, basic procedures and software solution. http://nbn-resolving. de/urn:nbn:de:0168-ssoar-395173. Retrieved January 20, 2020.

Miller-Jones, D., \& Greer, B. (2009). Conceptions of assessment of mathematical proficiency and their implications for culturally diversity. In B. Greer, S. Mukhopadhyay, A. B. Powell, \& S. Nelson-Barber (Eds.), Culturally responsive mathematics education (pp. 165-186). New York: Routledge.

Moschkovich, J. N. (2007). Beyond words to mathematical content: Assessing English learners in the mathematics classroom. In A. Schoenfeld (Ed.), Assessing mathematical proficiency (pp. 345352). New York: Cambridge University Press.

Moschkovich, J. N., \& Nelson-Barber, S. (2009). What mathematics teachers need to know about culture and language. In B. Greer, S. Mukhopadhyay, A. B. Powell, \& S. Nelson-Barber (Eds.), Culturally responsive mathematics education (pp. 111-137). New York: Routledge.

NDET. (2013). Curriculum for the common core subject of mathematics. http://www.udir.no/k106/MAT1-04/Hele/?lplang=eng. Retrieved January 20, 2020.

NDET [Norwegian Directorate for Education and Training]. (2012). Framework for basic skills. Oslo: NDET.

Nicol, C., Archibald, J.-A., \& Baker, J. (2013). Designing a model of culturally responsive mathematics education: Place, relationships and storywork. Mathematics Education Research Journal, 25, 73-89.

OECD. (2013). PISA 2012 assessment and analytical framework for mathematics, reading, science, problem solving and financial literacy. Paris: OECD Publishing.

OECD. (2015). Helping migrant students to succeed at school and beyond. Paris: OECD Publishing.

OECD. (2016a). PISA 2015 results. Excellence and equity in education. Paris: OECD Publishing.

OECD. (2016b). Skills matter: Further results from the survey of adult skills, tables of results. Paris: OECD Publishing. https:// doi.org/10.1787/9789264258051-9-en.

Prediger, S., Clarkson, P., \& Boses, A. (2016). Purposefully relating multilingual registers: building theory and teaching strategies for bilingual learners based on an integration of three traditions. In R. Barwell, P. Clarkson, A. Halai, M. Kazima, J. Moschkovich, N. Planas, M. Setati-Phakeng, P. Valero, \& M. Villavicencio Ubillús (Eds.), Mathematics Education and Language Diversity: The 21st ICMI Study (pp. 193-215). Cham: Springer. 
Roos, H. (2019). Inclusion in mathematics education: An ideology, a way of teaching, or both? Educational Studies in Mathematics, $100,25-41$.

Rousseau, C., \& Tate, W. F. (2003). No time like the present: Reflecting on equity in school mathematics. Theory into Practice, 42(3), $210-216$

Skovmose, O. (1994). Towards a critical mathematics education. Educational Studies in Mathematics, 27(1), 35-57.

Stobart, G. (2005). Fairness in multicultural assessment systems. Assessment in Education, 12(3), 275-287.
Taguma, M., Shewbridge, C., Huttove, J., \& Hoffman, N. (2009). OECD reviews of migrant education: Norway. Paris: OECD Publishing.

Publisher's Note Springer Nature remains neutral with regard to jurisdictional claims in published maps and institutional affiliations. 